\title{
Assembly with the NR1 Subunit Is Required for Surface Expression of NR3A-Containing NMDA Receptors
}

\author{
Isabel Pérez-Otaño, ${ }^{1}$ Christine T. Schulteis, ${ }^{1}$ Anis Contractor, ${ }^{1}$ Stuart A. Lipton, ${ }^{2}$ James S. Trimmer, ${ }^{3}$ \\ Nikolaus J. Sucher, ${ }^{4}$ and Stephen F. Heinemann ${ }^{1}$ \\ ${ }^{1}$ Molecular Neurobiology Laboratory, The Salk Institute for Biological Studies, La Jolla, California 92037, ${ }^{2}$ Center for \\ Neuroscience and Aging, The Burnham Institute, La Jolla, California 92037, ${ }^{3}$ Department of Biochemistry and Cell \\ Biology, State University of New York, Stony Brook, New York 11794, and ${ }^{4}$ Department of Biology, Hong Kong University \\ of Science and Technology, Hong Kong, China
}

Functional NMDA receptors are heteromultimeric complexes of the NR1 subunit in combination with at least one of the four NR2 subunits (A-D). Coexpression of NR3A, an additional subunit of the NMDA receptor family, modifies NMDA-mediated responses. It is unclear whether NR3A interacts directly with NR1 and/or NR2 subunits and how such association might regulate the intracellular trafficking and membrane expression of NR3A. Here we show that NR3A coassembles with NR1-1a and NR2A to form a receptor complex with distinct singlechannel properties and a reduced relative calcium permeability. NR3A associates independently with both NR1-1a and NR2A in the endoplasmic reticulum, but only heteromeric complexes containing the NR1-1a NMDA receptor subunit are targeted to

Glutamate receptors of the NMDA subtype are involved in a number of physiological and pathological processes in the brain, including synaptic plasticity, refinement of synaptic connections during development, and excitotoxicity (Choi, 1988; ConstantinePaton et al., 1990; Bliss and Collingridge, 1993; Tsien et al., 1996). Functional NMDA receptors are heteromultimeric complexes of the NR1 subunit and one or more of the four NR2 subunits (NR2A-D) (Monyer et al., 1992). Homomeric complexes containing only NR1 or NR2 do not form functional channels in mammalian expression systems. It takes the coexpression of both subunit types for the formation of fully functional channels that are efficiently inserted into the plasma membrane (McIlhinney et al., 1996).

Coassembly between the various NR1 and NR2 subunits generates functionally distinct types of NMDA receptors. Incorporation of different NR1 splice variants into NMDA receptor complexes influences receptor properties such as modulation by

\footnotetext{
Received July 11, 2000; revised Nov. 22, 2000; accepted Nov. 28, 2000.

This research was supported by a fellowship from the government of Navarra, Spain (I.P.-O.), an International Traveling Research Fellowship from The Wellcome Trust (A.C.), a National Research Service Award (C.T.S.), National Institutes of Health Grant R01 NS28709, grants from the McKnight and Adler Foundations (S.F.H) and the Research Grants Council Hong Kong (N.J.S.), and National Institutes of Health Grants R01 NS34383 to J.S.T. and P01 HD29587 and R01 EY05477 to S.A.L. We thank Kevin Sevarino for the NR3A cDNA, David Colquhoun for providing single-channel analysis software, Shigetada Nakanishi for the rat NR2A plasmid, and Diane M. Papazian for the Shaker B potassium channel cDNA and antibody. We also thank Tim Green, Juan Piña-Crespo, John Wesseling, and Alasdair Gibb for helpful discussions and Ouynh-Chi Phan for technical assistance.

Correspondence should be addressed to Dr. Isabel Pérez-Otaño, Molecular Neurobiology Laboratory, The Salk Institute for Biological Studies, 10010 North Torrey Pines Road, La Jolla, CA 92037. E-mail: otano@salk.edu.

Copyright (C) 2001 Society for Neuroscience $0270-6474 / 01 / 211228-10 \$ 15.00 / 0$
}

the plasma membrane. Homomeric NR3A complexes or complexes composed of NR2A and NR3A were not detected on the cell surface and are retained in the endoplasmic reticulum. Coexpression of NR1-1a facilitates the surface expression of NR3A-containing receptors, reduces the accumulation of NR3A subunits in the endoplasmic reticulum, and induces the appearance of intracellular clusters where both subunits are colocalized. Our data demonstrate a role for subunit oligomerization and specifically assembly with the NR1 subunit in the trafficking and plasma membrane targeting of the receptor complex.

Key words: NMDA receptor; glutamate; calcium permeability; single channel; surface expression; assembly; NR3A

zinc, polyamines, and protein kinase $\mathrm{C}$, as well as binding to intracellular proteins (Durand et al., 1993; Hollmann et al., 1993; Ehlers et al., 1996; Wyszynski et al., 1997; Lin et al., 1998). The NR2 subunit composition determines biophysical characteristics of the channel such as conductance, mean open time, and sensitivity to $\mathrm{Mg}^{2+}$ block (Monyer et al., 1992, 1994; Stern et al., 1992). In addition, NR2 is required for the clustering and synaptic localization of NMDA receptors via its interaction with proteins of the postsynaptic density protein PSD-95/SAP90 family, whereas only certain NR1 splice variants associate with members of this protein family (Kornau et al., 1995; Niethammer et al., 1996). Heteromeric combinations of NR1 and NR2 subunits are characterized by a high relative $\mathrm{Ca}^{2+}$ permeability (Burnashev et al., 1995; Schneggenburger, 1996). This ability to flux $\mathrm{Ca}^{2+}$ is essential for the special role that NMDA receptors play in synaptic plasticity and neurotoxicity (Malenka and Nicoll, 1999; Sattler et al., 1999).

An additional NMDA receptor subunit, NR3A, has been identified in mammalian brains. Coexpression of NR3A with both NR1 and NR2 in Xenopus oocytes reduces whole-cell currents and results in the appearance of NMDA-gated channels with a smaller unitary conductance, compared with receptors assembled from NR1 and NR2 subunits (Das et al., 1998). Mice lacking NR3A have increased NMDA responses and increased dendritic spine density in cerebrocortical neurons, suggesting that the NR3A subunit plays a role in CNS development and plasticity via modulation of NMDA receptor activity (Das et al., 1998). How NR3A assembles with the other subunits and what mechanisms govern its functional expression and subcellular localization remain unclear. 
To address these issues, we have analyzed the ability of NR3A to interact with other NMDA receptor subunits and the role that such assembly plays in the trafficking of functional NR3Acontaining receptors. We present biochemical evidence that NR3A first assembles with the other NMDA receptor subunits in the endoplasmic reticulum (ER) and can independently associate with either NR1 or NR2 subunits. However, only heteromeric complexes including the NR1-1a subunit are targeted to and properly inserted at the plasma membrane. In the absence of NR1-1a, NR3A subunits remain in the ER and are unable to access the cell surface. These results suggest that subunit assembly and subsequent ER export of properly assembled complexes constitute a key mechanism to control the plasma membrane targeting of NMDA receptors with defined subunit composition.

\section{MATERIALS AND METHODS}

Construction of NMDA receptor expression vectors. cDNAs encoding the rat NR1-1a and NR2A NMDA receptor subunits were subcloned into the pcDNA1-Amp mammalian expression vector (Invitrogen, Carlsbad, CA). For expression in mammalian cells, the rat NR3A cDNA was subcloned into pCINeo (Promega, Madison, WI). To allow the visualization of the NR3A subunit, the enchanced green fluorescent protein (EGFP) (Clontech, Palo Alto, CA) was inserted in-frame at the $\mathrm{N}$ terminus of NR3A after the predicted signal peptide (residue 33).

Electrophysiological recordings. Calcium phosphate coprecipitation was used to transfect human embryonic kidney 293 (HEK293) cells transiently with plasmids containing the rat NMDA subunits and a plasmid carrying the coding sequence for the CD8 surface antigen (generously supplied by Dr. B. Seed, Massachusetts General Hospital, Boston, MA). For all experiments, NR1-1a and NR2A were coexpressed with the NR3A subunit at a ratio of 1:2:2. Two to $3 \mathrm{~d}$ after transfection, cells were labeled with anti-CD8 antibody-coated beads (Dynal, Great Neck, NY), transferred to a recording chamber, and continuously perfused with HEPES-buffered extracellular solution, $\mathrm{pH} 7.4$, containing (in mM): $\mathrm{NaCl} 135, \mathrm{KCl} 5, \mathrm{CaCl}_{2} 1$, sucrose 20, glucose 10, and HEPES 5. All chemicals were from Sigma (St. Louis, MO) unless otherwise stated. Whole-cell recordings were made from cells labeled with CD8-coated beads. The pipette solution for whole-cell recording contained (in $\mathrm{mM}$ ): gluconolactone 140, $\mathrm{NaOH}$ 140, HEPES 10, EGTA 11, and $\mathrm{NaCl} 10$. NMDA (100 $\mu$; Research Biochemicals, Natick, MA) and glycine (20 $\mu \mathrm{M})$ were bath applied in an external solution containing either 1 or 10 $\mathrm{mM} \mathrm{Ca}{ }^{2+}$. Current-voltage $(I-V)$ relationships were constructed by performing voltage ramps generated by pClamp6 software (Axon Instruments, Foster City, CA). Each trial consisted of three $4 \mathrm{sec}$ ramps from -100 to $+40 \mathrm{mV}$. Ramps were performed before, during, and after drug application, and each set was averaged. The net $I-V$ plot was constructed by subtracting the averages of the trials before and after drug application from the average during drug application. After first correcting for the liquid junction potentials (Neher, 1992), measured to be $1.8 \mathrm{mV}$, shifts in current reversal potentials $\left(E_{\text {shift }}\right)$ were calculated by subtracting the current reversal potential in the presence of $1 \mathrm{~mm}$ external $\mathrm{Ca}^{2+}\left(E_{1}\right)$ from the reversal in $10 \mathrm{mM} \mathrm{Ca}^{2+}\left(E_{2}\right)$. This change in reversal potential was used to calculate the $\mathrm{Ca}^{2+}$ permeability ratio $\left(P_{\mathrm{Ca} 2+} / P_{\mathrm{Mono}+}\right)$ using the modified Goldman-Hodgkin-Katz equation (GHK) (Mayer and Westbrook, 1987). Assuming the intracellular $\mathrm{Ca}^{2+}$ concentration is negligible compared with the extracellular concentration, that all permeable monovalent cations have equal permeability and there is equal total monovalent activity on each side of the membrane, we used the following rearrangement of the GHK equation to calculate the $\mathrm{Ca}^{2+}$-tomonovalent permeability ratio:

$$
\frac{P_{\mathrm{Ca}}}{P_{\mathrm{M}}}=\frac{M_{o}\left\{1-\left(\exp \left[\frac{2\left(E_{1}-E_{2}\right)}{R T / F}\right]\right)\right\}}{\exp \left\{\frac{2\left(E_{1}-E_{2}\right)}{R T / F}\right\} 4 \mathrm{Ca}_{2}^{2+}-4 \mathrm{Ca}_{1}^{2+}},
$$

where $E_{1}$ and $E_{2}$ are reversal potentials measured in the presence of the $\mathrm{Ca}^{2+}$ concentrations $\mathrm{Ca}^{2+}{ }_{1}$ and $\mathrm{Ca}^{2+}{ }_{2}, R$ is the Gas constant, $T$ is the absolute temperature, and $F$ is the Faraday constant.

Single-channel recordings from HEK293 cells. For single-channel re- cordings, HEK293 cells were perfused with HEPES-buffered extracellular solution containing $1 \mathrm{mM} \mathrm{Ca}^{2+}$. Sylgard (Dow Corning, Midland, $\mathrm{MI})$ resin-coated electrodes with a tip resistance of 15-20 M $\Omega$ were used to make outside-out patch-clamp recordings, and channel openings were induced by application of NMDA and glycine into the bath.

Single-channel data analysis. Data records were stored on digital audiotape, filtered at $1-2 \mathrm{kHz}$, and continuously sampled at $10-20 \mathrm{kHz}$ onto a computer using a 1401 plus interface (Cambridge Electronic Design, Cambridge, UK). The records were analyzed using SCAN, a time course fitting program, kindly provided by David Colquhoun (University College London, London, UK), and distributions were constructed of the current amplitudes and open times (Colquhoun and Sigworth, 1995). Distributions of open times conditional on the amplitude of openings were constructed using a critical amplitude value $\left(A_{\text {crit }}\right)$ that was calculated from the parameters of the Gaussian components fitted to the amplitude distributions (Colquhoun and Sigworth, 1995).

Immunoprecipitation and immunoblotting. NMDA receptor subunits were heterologously expressed in HEK293T cells [formerly TsA201 cells (Dubridge et al., 1987)]. When NR1-1a/NR2A or NR1-1a/NR2A/ NR3A combinations were transfected, $1 \mathrm{~mm}$ AP-5 and $1 \mathrm{~mm}$ kynurenate were included in the culture media to prevent NMDA receptor-mediated cell death. Two to $3 \mathrm{~d}$ after transfection, the cells were washed in PBS and subsequently lysed by the addition of lysis buffer (50 mM Tris, pH 9.0, and $1 \%$ deoxycholate) containing the following protease inhibitors: 0.5 $\mathrm{mM}$ PMSF, $50 \mu \mathrm{g} / \mathrm{ml}$ antipain, $25 \mu \mathrm{g} / \mathrm{ml}$ APMSF, $40 \mu \mathrm{g} / \mathrm{ml}$ bestatin, 2 $\mu \mathrm{g} / \mathrm{ml}$ aprotinin, $0.5 \mu \mathrm{g} / \mathrm{ml}$ leupeptin, $0.7 \mu \mathrm{g} / \mathrm{ml}$ pepstatin, and $0.1 \mathrm{~mm}$ EDTA (Sigma or Boehringer Mannheim, Indianapolis, IN). HEK293T cell lysates were solubilized for $30 \mathrm{~min}$ at $37^{\circ} \mathrm{C}$, and insoluble material was removed by centrifugation at $100,000 \times g$ for 30 min. Resulting

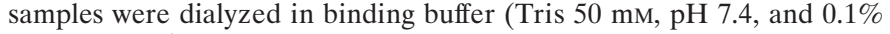
Triton X-100) overnight at $4^{\circ} \mathrm{C}$ to avoid interference of the detergent during immunoprecipitation (Luo et al., 1997). Protein was immunoprecipitated by a $2 \mathrm{hr}$ incubation in either mouse anti-NR1 (1:200 dilution; PharMingen, La Jolla, CA), rabbit anti-NR2A/B (1:100 dilution; Chemicon, Temecula, CA), or mouse anti-NR3A (clone K35/40; 1:25 dilution of crude ascites) antibodies, followed by a $45 \mathrm{~min}$ incubation in Protein A Sepharose (Pharmacia, Piscataway, NJ) or Protein A/G agarose beads (Calbiochem, La Jolla, CA). The beads were extensively washed, and the samples were boiled in Laemmli SDS sample buffer for subsequent electrophoresis and immunoblotting. For enzymatic deglycosylation, immunoprecipitated samples were resuspended in reaction buffer $(100 \mathrm{~mm}$ $\mathrm{NaCl}, 1 \mathrm{mM} \mathrm{CaCl}_{2}$, and $50 \mathrm{~mm}$ Tris, $\mathrm{pH}$ 8.0) supplemented with protease inhibitors, incubated for 12-14 hr at room temperature in the presence or absence of $1 \mathrm{U}$ of $N$-glycosidase F (Boehringer Mannheim), and boiled in Laemmli sample buffer.

Immunoprecipitated proteins were subjected to SDS-PAGE on $7.5 \%$ separating gels with $4 \%$ stacking gels. Proteins were transferred to Immobilon P membranes (Millipore, Bedford, MA) and immunoblotted as described previously (Stern-Bach et al., 1994). Immunoblots were developed by chemiluminescence (Amersham, Arlington Heights, IL). Antibodies and dilutions used were as follows: anti-NR3A, clone K35/40 tissue culture supernatant, 1:20; anti-NR1, 1:500; anti-NR2A/B, antiglutamate receptor 1 (-GluR1), anti-GluR2/3, 1:100 (Chemicon); and rabbit anti-calreticulin, 1:1000 (Affinity Bioreagents, Golden, CO). The NR3A mouse monoclonal antibody was generated against a glutathione$S$-transferase fusion protein containing a region of the extracellular loop between transmembrane domains III and IV of NR3A (amino acids 780-914). The hybridoma clone $\mathrm{K} 35 / 40\left(\mathrm{IgG}_{1}\right)$ was used in this study. Antibody specificity was tested in our heterologous expression system (see Results).

Metabolic labeling experiments. At 36-48 hr after transfection, transfected HEK293T cells were incubated for $30 \mathrm{~min}$ in methionine- and cysteine-free DMEM (Mediatech, Herndon, VA) and subsequently pulsed for $20 \mathrm{~min}$ with $200 \mu \mathrm{Ci} / \mathrm{ml}{ }^{35} \mathrm{~S}$-labeled methionine (EasyTag Express Protein Labeling Mix; DuPont NEN, Boston, MA). Cells were then washed in PBS and chased in complete media, which in some cases was supplemented with $5 \mathrm{~mm}$ methionine. After the chase, the cells were washed in ice-cold PBS and lysed by the addition of cold RIPA buffer (10 mM phosphate buffer, pH 7.4, $150 \mathrm{~mm} \mathrm{NaCl}, 1 \%$ deoxycholate, $1 \%$ NP-40, and $0.1 \%$ SDS). Insoluble material was removed by a 15 min spin at $15,000 \mathrm{rpm}$, and the resulting samples were subjected to immunoprecipitation, SDS-PAGE (as described above), and autoradiography.

Brefeldin A (BFA) and nocodazole treatment was performed as described previously (Nagaya and Papazian, 1997). Briefly, cells were incubated in methionine- and cysteine-free DMEM containing $20 \mu \mathrm{g} / \mathrm{ml}$ 
nocodazole for $40 \mathrm{~min}$ followed by continued starvation in DMEM containing $20 \mu \mathrm{g} / \mathrm{ml}$ nocodazole and $5 \mu \mathrm{g} / \mathrm{ml} \mathrm{BFA}$ for $30 \mathrm{~min}$. Control experiments were performed with vehicle (DMSO). The subsequent pulse and chase were performed as described above, in the presence and absence of BFA and nocodazole.

Cell surface biotinylation. At $48 \mathrm{hr}$ after transfection, transfected HEK293T cells were washed in borate buffer $(100 \mathrm{~mm} \mathrm{NaCl}$, and $10 \mathrm{~mm}$ borate, $\mathrm{pH} 8.8$ ) and incubated in borate buffer with $0.05 \mathrm{mg} / \mathrm{ml}$ sulfoNHS-biotin (Pierce, Rockford, IL). After $10 \mathrm{~min}$, fresh reagent was added, and the cells were incubated an additional $10 \mathrm{~min}$. The reaction was quenched with $15 \mathrm{~mm} \mathrm{NH}_{4} \mathrm{Cl}$. The cells were washed in $100 \mathrm{~mm}$ $\mathrm{NaCl}$ and $50 \mathrm{~mm}$ Tris- $\mathrm{HCl}, \mathrm{pH} 7.5$ and lysed in $1 \%$ deoxycholate, and insoluble material was removed by centrifugation at $15,000 \mathrm{rpm}$ for 15 min. Biotinylated protein was precipitated in a $2 \mathrm{hr}$ incubation in streptavidin-agarose beads (Sigma). The beads were washed extensively and resuspended in Laemmli SDS sample buffer before electrophoresis and immunoblotting.

Cell surface localization studies using GFP-tagged NR3A. Different combinations of NR1-1a, NR2A, and GFP-tagged NR3A were expressed in HEK293T cells. At $48 \mathrm{hr}$ after transfection, cells were incubated with the cell surface marker Concanavalin A conjugated to tetramethylrhodamine (100 $\mu \mathrm{g} / \mathrm{ml}$; Molecular Probes, Eugene, OR) for $5 \mathrm{~min}$ at $37^{\circ} \mathrm{C}$, washed twice with ice-cold PBS, and fixed with $4 \%$ paraformaldehyde for $5 \mathrm{~min}$. Coverslips were mounted in SlowFade mounting medium (Molecular Probes). The cells were then observed with an LSM 510 Zeiss laser-scanning confocal microscope using a $40 \times$ oil immersion lens and a pinhole of 112. GFP fluorescence was excited using a $488 \mathrm{~nm}$ argon/krypton laser, and emitted fluorescence was detected with a 515$540 \mathrm{~nm}$ bandpass filter. For detection of tetramethylrhodamineconjugated Concanavalin A, a $568 \mathrm{~nm}$ argon/krypton laser was used for excitation, and fluorescence was detected with a $590 \mathrm{~nm}$ bandpass filter. There was no bleed through of fluorescence between the channels under the conditions used for these experiments. All observations were made blind. The acquired images were analyzed using Zeiss KS300 software, and masks of the overlapping red and green fluorescence were generated. Fluorescence pixels of the total green fluorescence (total receptor expression) and of green fluorescence in the colocalization mask (receptor at the cell surface) were measured. The relative percentage of the receptor on the cell surface was estimated as the ratio of green fluorescence pixels at the colocalization mask and total green fluorescence.

Immunocytochemistry. At $48 \mathrm{hr}$ after transfection, immunofluorescence was performed in nonpermeabilized HEK293T cells to detect surface expression of NMDA receptors. The cells were fixed with icecold $4 \%$ paraformaldehyde in PBS for 10 min. After blocking with $5 \%$ bovine serum albumin in PBS for $30 \mathrm{~min}$, cells were incubated with the monoclonal anti-NR1 antibody, which reacts with the extracellular loop between transmembrane domains III and IV (1:500 dilution; PharMingen), and rabbit (1:3000; Clontech) or chicken (1:3000; Chemicon) anti-GFP antibody overnight at $4^{\circ} \mathrm{C}$. After washing, the cells were incubated with indocarbocyanine (Cy3)-conjugated goat anti-mouse (1: 600 dilution; Jackson ImmunoResearch, West Grove, PA) and FITCconjugated goat anti-rabbit (1:600 dilution; Vector Laboratories, Burlingame, CA) or Texas Red-conjugated goat anti-chicken (1:1000 dilution; Chemicon) secondary antibodies for $1 \mathrm{hr}$ at room temperature. For immunostaining with rabbit anti-calreticulin (1:200) and mouse antiGrp78 (1:200; Stressgen Biotechnologies, Victoria, British Columbia, Canada) antibodies, cells were permeabilized with $0.1 \%$ Triton $\mathrm{X}-100$ in PBS for $10 \mathrm{~min}$ before addition of the primary antibody. Biotinylated anti-rabbit secondary antibody (1:1000; Vector Laboratories) followed by avidin-Texas Red (1:1000; Vector Laboratories) or Cy3-conjugated antimouse antibody (1:600; Jackson ImmunoResearch) was used. Cells were then washed and mounted, and images were acquired using a Zeiss confocal microscope.

\section{RESULTS}

\section{Coexpression of NR3A with NR1-1a and NR2A in HEK293 cells results in the appearance of two types of NMDA receptors}

To test the ability of HEK293 cells to process functional NMDA receptors incorporating the NR3A subunit, we analyzed the electrophysiological properties of recombinant NMDA receptors in transiently transfected cells. NR3A did not form functional channels when expressed alone in HEK293 cells, as shown pre- viously in Xenopus oocytes (Ciabarra et al., 1995; Sucher et al., 1995). Functional NMDA channels were also not detected after expression of either NR1-1a and NR3A or NR2A and NR3A. Only HEK293 cells expressing NR1-1a and NR2A or NR1-1a, NR2A, and NR3A generated NMDA-activated currents.

To determine whether the NR3A subunit was included in heteromeric complexes containing NR1-1a and NR2A subunits, we measured the single-channel properties of NMDA receptors in outside-out patches pulled from cells transfected with cDNAs encoding the NR1-1a, NR2A, and NR3A subunits. Two distinct channel types were observed after application of NMDA (0.5-5 $\mu \mathrm{M})$ and glycine $(0.5 \mu \mathrm{M})$ in patches from cells expressing all three subunits. These channels could be differentiated by their characteristic conductance states (Fig. $1 A$ ). One of the channel populations had a conductance of $47.9 \pm 2.1 \mathrm{pS}$ (mean \pm SEM; $n=4$; $-70 \mathrm{mV}$ ) and a mean open time of $3.1 \pm 0.9 \mathrm{msec}$, similar to the values described for NR1-1a/NR2A receptors (Stern et al., 1992). The second channel population had a significantly lower conductance of $28.1 \pm 4.1 \mathrm{pS}(n=4 ;-70 \mathrm{mV} ; p<0.05$, paired $t$ test), similar to the value described previously for NMDA channels incorporating NR3A in oocytes (Das et al., 1998), and a longer mean open time of $6.7 \pm 1.9 \mathrm{msec}$ (Fig. $1 A-C$ ). The low-conductance channel was not a subconductance state, because analysis of the conductances showed that there were no direct transitions between the 28 and the $48 \mathrm{pS}$ conductance levels. The $28 \mathrm{pS}$ conductance was present only when NR3A was cotransfected with the other NMDA subunits and never in cells expressing just NR1-1a and NR2A. Because cells expressing only NR1-1a and NR3A, or NR2A and NR3A, do not produce NMDA-activated currents, this low conductance is likely attributable to channels composed of NR1-1a, NR2A, and NR3A subunits.

\section{NMDA receptors containing the NR3A subunit display a low relative $\mathrm{Ca}^{2+}$ permeability}

One critical feature of NMDA receptors is their high relative $\mathrm{Ca}^{2+}$ permeability. Because a previous report indicated that NMDA receptors containing NR3A expressed in oocytes may be less permeable to $\mathrm{Ca}^{2+}$ than heteromeric combinations of NR1 and NR2 subunits (Das et al., 1998), we studied the influence of the NR3A subunit on the $\mathrm{Ca}^{2+}$ permeability of recombinant NMDA receptors in HEK293 cells. We estimated the fraction of the total current carried by $\mathrm{Ca}^{2+}$ ions through recombinant NMDA receptors by measuring the reversal potential of the NMDA-activated whole-cell currents in 1 and $10 \mathrm{~mm}$ external $\mathrm{Ca}^{2+}$. After correction for the liquid junction potential (Neher, $1992)$, the shift in reversal potential $\left(E_{\text {shift }}\right)$ for the NR1-1a/ NR2A combination was $-7.4 \pm 2.3 \mathrm{mV}(n=7$; Fig. $1 D)$. This corresponds to a $P_{\mathrm{Ca} 2+} / P_{\mathrm{Mono}+}$ of 3.4 , in agreement with previously published data (Schneggenburger, 1996). When NR3A was cotransfected with NR1-1a and NR2A, the average $E_{\text {shift }}$ was $-1.6 \pm 2.1 \mathrm{mV}(n=4$; Fig. $1 E)$, corresponding to a relative divalent ion permeability of 0.6. Thus, the addition of the NR3A subunit resulted in a fivefold decrement in the relative $\mathrm{Ca}^{2+}$ permeability of the whole-cell NMDA current.

\section{NR3A specifically coimmunoprecipitates with NR1-1a and NR2A}

To test whether this second type of NMDA receptor channel was a result of NR3A forming stable complexes with other NMDA receptor subunits, we performed coimmunoprecipitation experiments. NR3A was coexpressed with NR1-1a, NR2A, or NR1-1a 
A

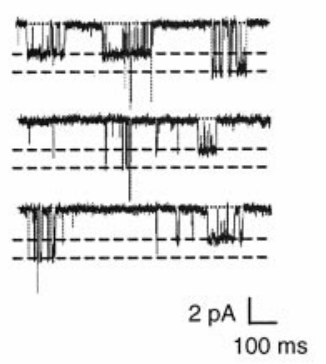

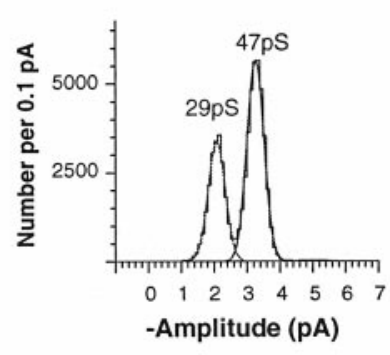

$\mathrm{P}_{\mathrm{Ca} 2+\mathrm{Na}+}=3.4$

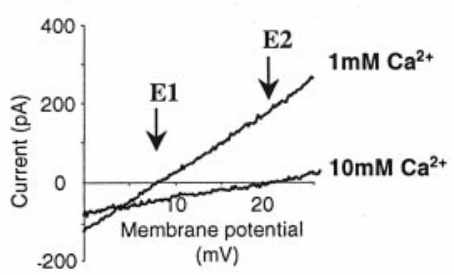

$-200$
B

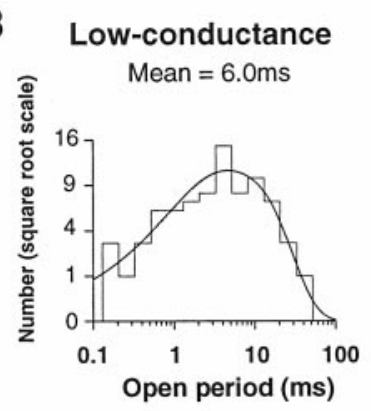

E

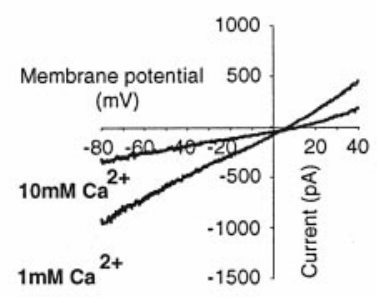

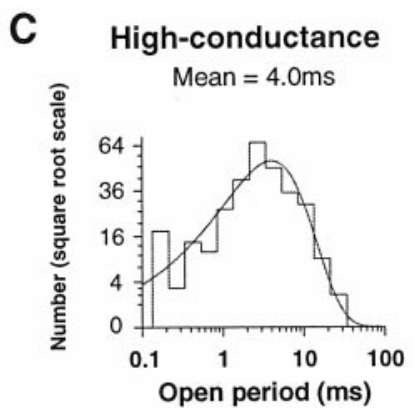

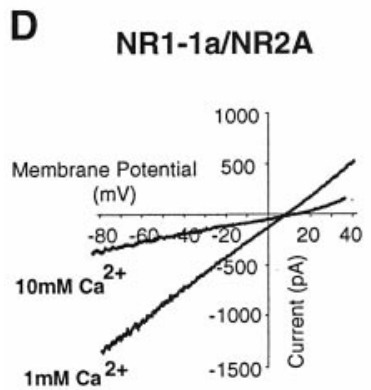

Figure 1. Functional properties of NR1-1a/NR2A/NR3A channels in HEK293 cells. $A$, Single-channel openings induced by application of $5 \mu$ M NMDA and $0.5 \mu \mathrm{M}$ glycine to an outside-out patch held at $-70 \mathrm{mV}$. Left, Openings to two distinct conductance levels, 29 and $47 \mathrm{pS}$, that were seen in this recording. Right, The amplitude histogram constructed from the fitted data that shows two peaks corresponding to two distinct channels. The $47 \mathrm{pS}$ conductance is in agreement with the previously published value for NR1-1a/NR2A channels (Stern et al., 1992). The 29 pS conductance is attributable to channels composed of NR1-1a/NR2A/NR3A subunits. $B$, Open period histogram of the low-conductance (29 pS) NR3A-containing channel ( $\tau$, area; $1.9 \mathrm{msec}, 12 \% ; 12 \mathrm{msec}, 88 \%)$. C, Open period histogram of the high conductance (47 pS) NR1-1a/NR2A channel. The histogram is fitted with the sum of two exponential components ( $\tau$, area; $0.1 \mathrm{msec}, 21 \% ; 4.7 \mathrm{msec}, 79 \%) . D$, E, Representative examples of voltage ramps performed on HEK293 cells transfected with NR1-1a/NR2A alone or with NR3A. $E_{\text {shift }}$ was calculated as follows: $E_{\text {shift }}=\left(E_{1}\right)-\left(E_{2}\right)$, where $\left(E_{1}\right)=$ reversal in 1 mM Ca ${ }^{2+}$ and $\left(E_{2}\right)=$ reversal in $10 \mathrm{mM} \mathrm{Ca}^{2+}$. In the example shown, $E_{\text {shift }}$ is measured as $-11.5 \mathrm{mV}$ for NR1-1a/NR2A receptors $(D)$ and $-5.93 \mathrm{mV}$ for NR1-1a/NR2A/NR3A $(E)$. Values for $E_{\text {shift }}$ were used to calculate the relative $\mathrm{Ca}^{2+}$ permeability $\left(P_{\mathrm{Ca} 2+} / P_{\mathrm{Mono}+}\right)$ (see Materials and Methods). Numbers shown for relative $\mathrm{Ca}^{2+}$ permeability correspond to the mean of $n=7$.

and NR2A in HEK293T cells. For immunodetection of the NR3A subunit, we used a monoclonal antibody directed against an extracellular epitope of NR3A located between the predicted transmembrane domains III and IV. Immunoblot analysis of crude lysates from cells transfected with NR3A resulted in a single band of $\sim 130 \mathrm{kDa}$. This band was absent in mocktransfected cells and cells transfected with only NR1-1a and NR2A, demonstrating the specificity of the NR3A antibody (Fig. $2 A$, top blot). After coexpression with NR1-1a or NR1-1a and NR2A, a second, fainter band of higher molecular weight $(\sim 140$ $\mathrm{kDa}$ ) was observed. This upper band corresponds to a difference in N-linked glycosylation of the NR3A protein in the presence of NR1-1a, because treatment with $N$-glycosidase F makes both bands collapse into a single band of $\sim 115 \mathrm{kDa}$, in agreement with the expected molecular size of the NR3A polypeptide (Fig. $2 C$ ).

The NR1-1a and NR2A subunits were immunoprecipitated from transfected cell lysates using anti-NR1 and anti-NR2A/B antibodies. NR3A coimmunoprecipitated with both NR1-1a $(116 \mathrm{kDa})$ and NR2A (180 kDa) when all three subunits were coexpressed (Fig. 2B). Coimmunoprecipitation was also observed when either NR1-1a or NR2A was expressed with NR3A, demonstrating that both NR1 and NR2 subunits are able to associate independently with NR3A. In control experiments, NR3A, when expressed by itself, did not immunoprecipitate with NR1 or NR2A/B antibodies. This excludes the possibility that NR3A could be pulled down nonspecifically by these antibodies (Fig. 2B).

The anti-NR3A antibody did not coimmunoprecipitate the
AMPA receptor subunits GluR1 or GluR2 when coexpressed with NR3A in HEK293T cells (Fig. 2D). These results demonstrate subfamily-specific assembly of NR3A with the NR1-1a and NR2A NMDA receptor subunits in mammalian cells.

\section{Association of NR3A with NR1-1a and NR2A occurs in the endoplasmic reticulum}

To identify the intracellular compartment in which NR3A first associates with NR1 and NR2A subunits, metabolically labeled, transfected cells were treated with BFA and nocodazole. This drug combination inhibits protein transport from the ER to the Golgi apparatus (Lippincott-Schwartz et al., 1990; Klausner et al., 1992).

NR3A association with the other NMDA receptor subunits was then evaluated by coimmunoprecipitation. Figure $3 A$ shows the results of one such experiment in which NR2A and NR3A proteins coimmunoprecipitate with NR1-1a subunits in both the presence and absence of BFA/nocodazole. Immunoprecipitation with anti-NR2A and anti-NR3A antibodies allowed clear identification of the NR2A and NR3A protein bands in the autoradiogram. However, these antibodies were unable to coimmunoprecipitate detectable levels of the other associating receptor subunits under the conditions of solubilization used for the pulsechase experiments. The effectiveness of BFA/nocodazole treatment was verified in parallel experiments with the Shaker B K ${ }^{+}$ channel protein, which demonstrated the expected shift in molecular mass after BFA/nocodazole treatment (Fig. 3B) (Nagaya and Papazian, 1997). These data demonstrate that NR3A-containing 
A

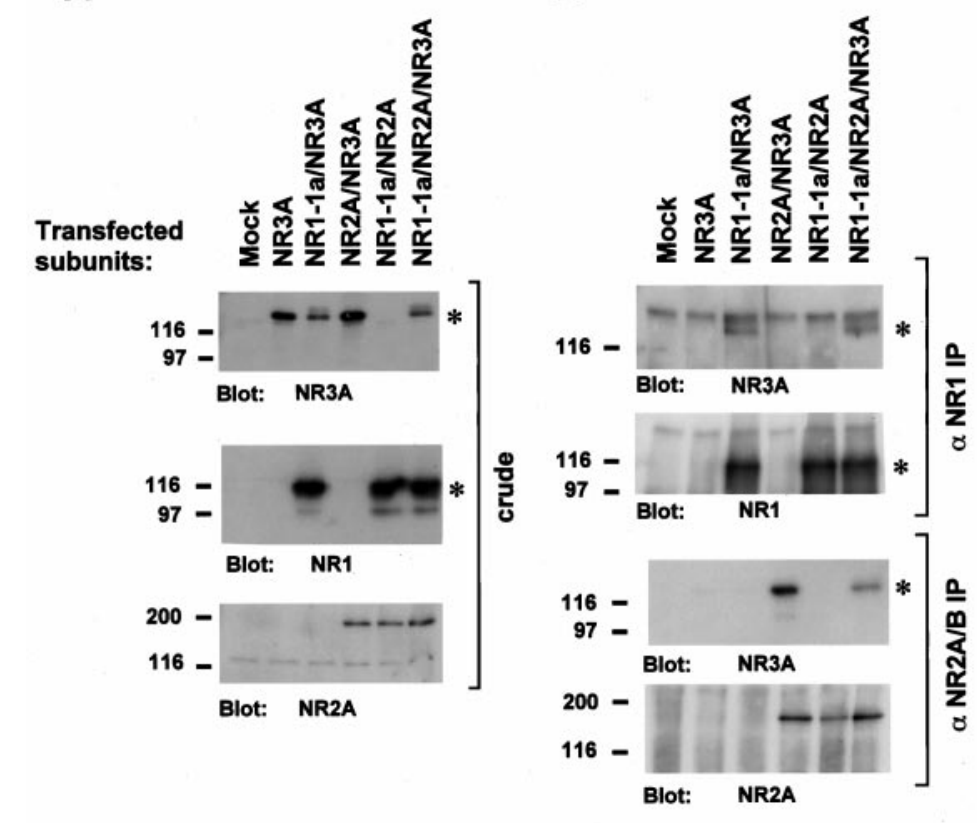

C

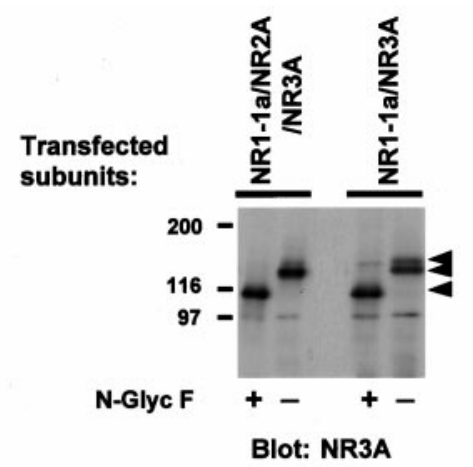

Blot: NR3A

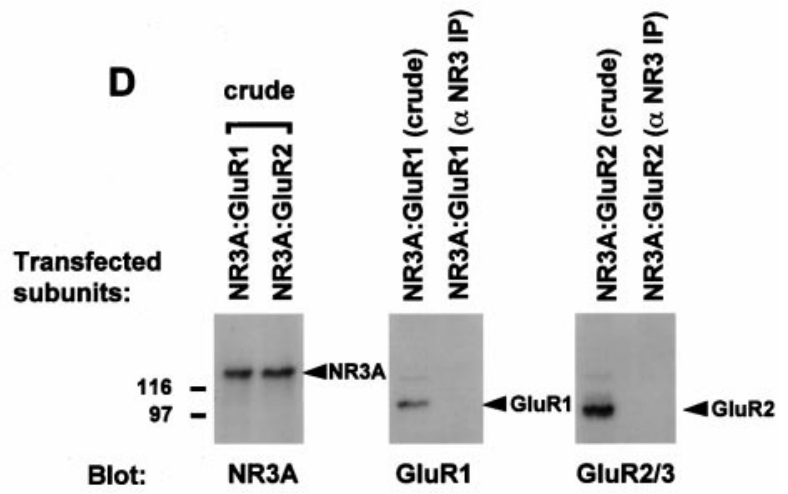

Figure 2. NR3A coimmunoprecipitates with the NMDA receptor subunits NR1-1a and NR2A. A, Crude lysates from mock-transfected HEK293T cells or cells transfected with the combinations of NMDA subunits indicated above each lane were immunoblotted with anti-NR3A, anti-NR1, or anti-NR2A/B antibodies to verify expression of the corresponding subunits after transfection. $B$, NMDAR subunits were immunoprecipitated from HEK293T cell lysates using anti-NR1 and anti-NR2A/B antibodies. Immunoprecipitates were immunoblotted for NR1, NR2A, and NR3A as indicated. Asterisks mark the bands corresponding to NR1-1a and NR3A. Additional bands derive from nonspecific binding to the secondary antibody because they are present when the primary antibody is excluded (data not shown). $C$, NR3A is differentially glycosylated in the presence of the NR1-1a subunit. Lysates of HEK293T cells transfected with NR1-1a/NR3A or NR1-1a/NR2A/NR3A were immunoprecipitated with anti-NR3A antibodies, treated with $\mathrm{N}$-glycosidase F $(N$-Glyc $F)$, or mock digested as indicated and analyzed by immunoblotting with anti-NR3A antibody. Arrowheads indicate the position of the glycosylated (top arrowheads) and deglycosylated (bottom arrowhead) forms of NR3A. Both differentially glycosylated forms behaved similarly in coimmunoprecipitation and biotinylation experiments. $D$, The specificity of coimmunoprecipitation was tested by coexpression of NR3A with non-NMDA glutamate receptors. NR3A was cotransfected with GluR1 and GluR2, and lysates were immunoprecipitated with anti-NR3A antibody. Immunoprecipitates were probed with anti-GluR1 or anti-GluR2/3 antibodies. Lanes labeled crude contain $2 \%$ of the cell lysate used for immunoprecipitation and demonstrate expression of NR3A, GluR1, and GluR2. The bands specific for NR3A, GluR1, and GluR2 are indicated. Positions of molecular size markers in kilodaltons are shown on the left. IP, Immunoprecipitate.

NMDA receptors assemble early in the biosynthetic pathway, at the level of the ER, as is the case for most ion channel subunits (Green and Millar, 1995) and as reported previously for NR1 and NR2A (McIlhinney et al., 1998).

\section{NR3A requires the presence of NR1-1a for cell surface expression}

Proper assembly is often a prerequisite for expression of ion channels on the cell surface (Green and Millar, 1995; Gorrie et al., 1997; Zerangue et al., 1999). NR3A does not form functional homomeric channels in HEK293 cells, although immunoblots demonstrate high expression levels of the NR3A subunit (see Fig. $2 A$ ). To study whether assembly is required for the surface targeting of the NR3A subunit, we analyzed the plasma membrane expression of NR3A and how it is altered by coexpression of other NMDA receptor subunits.

Membrane proteins were biotinylated using a membraneimpermeant biotinylation agent and were recovered by streptavidin precipitation (Fig. 4A, lanes labeled 2). As shown in Figure $4 A$, top blot, NR3A was not detected at the cell surface when expressed alone or in combination with the NR2A subunit. However, coexpression of NR3A with NR1-1a or both NR1-1a and
NR2A resulted in the appearance of NR3A in the plasma membrane fraction. The higher molecular weight band, which appears only when NR3A is cotransfected with the NR1-1a subunit, was enriched in the plasma membrane fraction, although both forms of NR3A can reach the cell surface. As expected, NR1-1a and NR2A were present at the cell surface when all three subunits were expressed (Fig. 4A, bottom blots). Immunoblot analysis indicated that coexpression did not induce changes in NR3A protein expression levels that could account for this difference in surface labeling (see Fig. 4A, lanes labeled 1). Control experiments showed that the ER resident protein calreticulin was absent in the streptavidin-precipitated material, confirming that only cell surface proteins were recovered (Fig. 4A). These data show that NR3A is not targeted to the plasma membrane without coexpression of the NR1 subunit.

To visualize the subcellular localization of the NR3A subunit and how this distribution is affected by the presence of NR1, we tagged NR3A with GFP by inserting GFP at the N terminus of the receptor, immediately after the signal peptide sequence (Fig. $4 B$ ). Transfection of the NR3A-GFP construct gave a single protein band of the expected molecular weight when analyzed by 
A

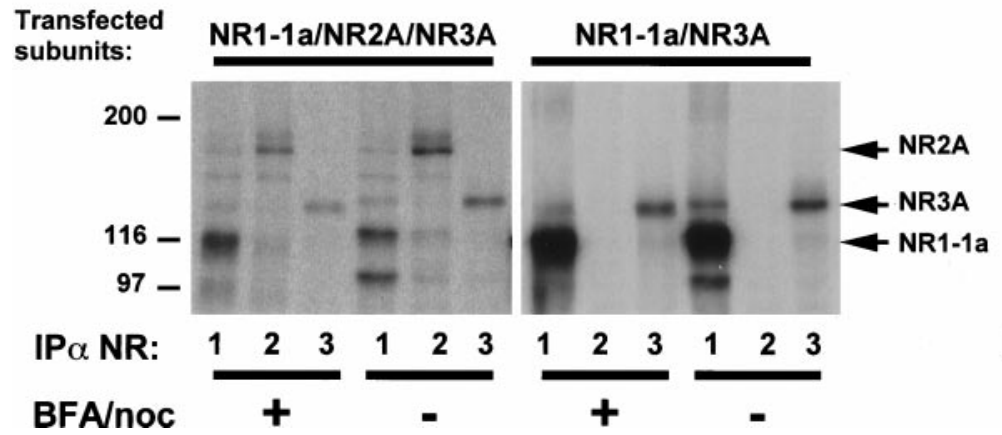

B

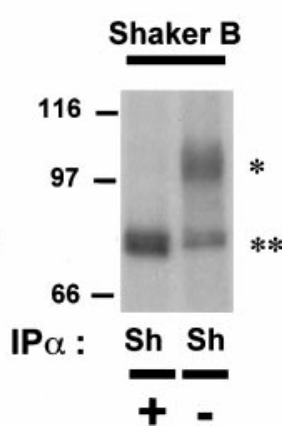

Figure 3. NR3A assembles with NR1-1a and NR2A in the endoplasmic reticulum. Transfected HEK293T cells were metabolically labeled and treated with either BFA/nocodazole, to block ER-to-Golgi transport, or DMSO vehicle. A, Autoradiograms of transfected cell lysates immunoprecipitated with antibodies against (IP $\alpha$ ) NR1 (lanes labeled 1), NR2A/B (lanes labeled 2), or NR3A (lanes labeled 3) are shown. All three receptor subunits were immunoprecipitated by the anti-NR1 antibody in both the drug treatment and vehicle controls, demonstrating that blockade of protein transport did not prevent incorporation of NR3A into NMDA receptor complexes (NR1-1a/NR2A/NR3A). NR1-1a and NR3A subunits are also shown to assemble in the ER. The NR2A/B and NR3A antibodies were less efficient at coimmunoprecipitation under these solubilization conditions but demonstrate the identity of the NR2A and NR3A protein bands, respectively. Small decreases in the molecular mass of NR1-1a and NR3A after treatment with BFA/nocodazole suggest that some post-translational processing of the protein takes place in the Golgi apparatus. Additional bands between NR2A and NR3A and below NR1-1a are likely to be either degradation products or precursors of NR2A and NR1-1a, respectively. B, The Shaker B potassium channel subunit was expressed and immunoprecipitated in a parallel experiment. The failure of the Shaker protein to convert from the immature, ER-resident, form (double asterisks) to the mature form (single asterisk) in the presence of BFA/nocodazole verified the effectiveness of the drug treatment in blocking ER-to-Golgi transport. Representative experiments are shown; $n=3$. Positions of molecular size markers in kilodaltons are shown on the left. noc, nocodazole; Sh, Shaker.

immunoblot with anti-NR3A (Fig. 4B) and anti-GFP antibodies (data not shown). Voltage-clamp studies in oocytes showed that introduction of the GFP tag does not alter the functional characteristics of NR3A (J. Piña-Crespo and I. Pérez-Otaño, unpublished observations).

According to the predicted transmembrane topology of glutamate receptors, the GFP tag should be located on the extracellular surface of the mature receptor (Fig. 4B) (Hollmann et al., 1994; Wo and Oswald, 1994). Incubating nonpermeabilized cells with antibodies directed against GFP should therefore label only the fraction of NR3A that is correctly inserted at the plasma membrane such that the $\mathrm{N}$-terminal domain is exposed to the extracellular media. We labeled nonpermeabilized cells with an anti-GFP antibody followed by a Texas Red-conjugated secondary antibody. This allowed us to differentiate the total cellular pool of channel subunits (green fluorescence) from the NR3AGFP that has been targeted to the plasma membrane (anti-GFP antibody labeled, red or yellow fluorescence). NR3A-GFP remained in the intracellular compartment when expressed alone or together with the NR2A subunit, as shown by the lack of surface labeling with anti-GFP antibody in intact cells (Fig. 4C, top panels). A strong perinuclear and reticular green fluorescence pattern was observed, suggesting that NR3A-GFP accumulates in the ER. Coexpression of NR1-1a, however, resulted in the appearance of intense surface labeling (Fig. 4C, bottom left panel), confirming the surface biotinylation results. When NR1-1a and NR2A were cotransfected with NR3A-GFP, we consistently observed that a higher fraction of green fluorescence remained in the intracellular compartment when compared with cells expressing NR1-1a and NR3A-GFP (Fig. 4C, bottom right panel). No surface fluorescence was ever detected in the absence of NR1-1a expression.

To measure the relative amount of NR3A located at the cell surface, we analyzed the degree of colocalization of NR3A-GFP fluorescence with the cell surface marker Concanavalin A conjugated to the red fluorochrome tetramethylrhodamine. As shown in Figure $5 A$, cotransfection of NR1-1a and NR2A increased the amount of NR3A-GFP at the cell surface as monitored by the overlapping fluorescence pattern. With this method, a small fraction of the NR3A-GFP fluorescence was estimated to be at the plasma membrane $(5.2 \pm 0.6 \% ; n=37$ cells $)$ when NR3A-GFP was expressed alone. Coexpression of NR1-1a increased the percentage of NR3A that resides on the cell surface to $35.1 \pm$ $3.6 \%(n=39)$. The amount of NR3A-GFP located at the surface of the cell was significantly lower when both NR1-1a and NR2A were coexpressed in comparison with cells expressing NR1-1a and NR3A-GFP $(19.6 \pm 2.0 \% ; n=35 ; p<0.001$; Fig. $5 B)$. This may reflect a limiting number of NR1 subunits available to complex with NR3A because of the formation of NMDA channels composed of NR1-1a/NR2A.

\section{NR3A is retained in the endoplasmic reticulum in the absence of the NR1-1a subunit}

Without the NR1 subunit, NR3A complexes are not inserted at the plasma membrane. The inability of NR3A to traffic to the cell surface could be caused by retention at a quality control checkpoint in the biosynthetic pathway (Ellgaard et al., 1999). Fluorescence microscopy was used to identify the intracellular compartments where NR3A was found in the absence of the NR1-1a subunit. When NR3A-GFP was expressed alone or together with NR2A, it was retained in the ER where it colocalized with the ER resident proteins calreticulin (Fig. 6) and Grp78 (data not shown). In the presence of NR1-1a, there was still significant overlap of NR3AGFP with ER markers, as expected because this compartment is the site where synthesis, folding, and assembly occur. However, coexpression with NR1-1a reduced the ER retention of NR3AGFP, as we observed intracellular patches of green fluorescence that did not colocalize with calreticulin (Fig. 6, bottom panels) or 


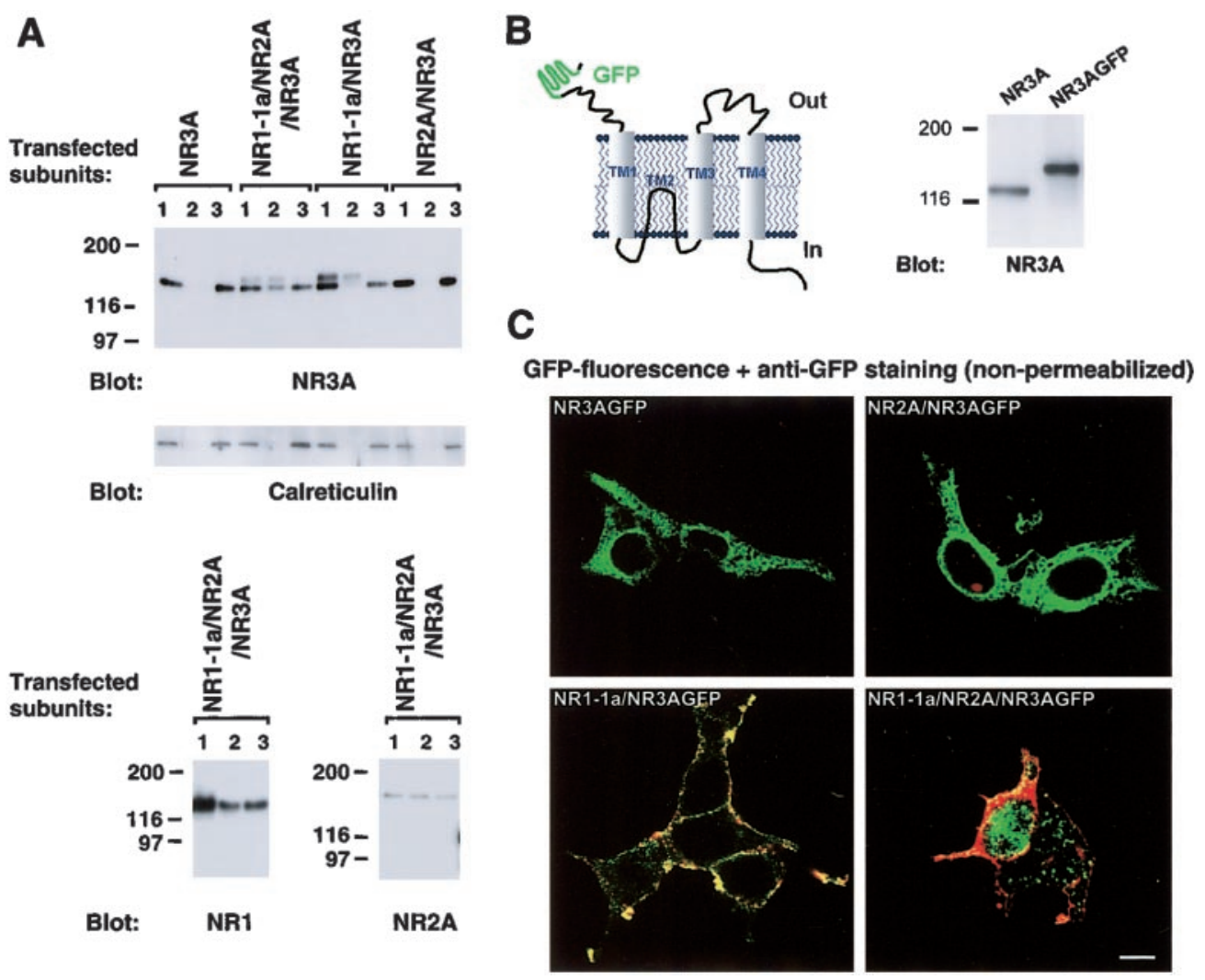

Figure 4. NR3A is present at the cell surface only when coexpressed with the NR1-1a subunit. $A$, HEK293T cells were transfected with different combinations of NMDA receptor subunits and incubated for $15 \mathrm{~min}$ with sulfo-NHS-biotin. After solubilization, biotinylated protein was recovered by streptavidin precipitation. The streptavidin fractions (lanes labeled 2), representing the membrane proteins, and aliquots of the lysate before (lanes labeled 1) and after (lanes labeled 3) streptavidin precipitation were analyzed by immunoblotting using anti-NR1, anti-NR2A/B, anti-NR3A, and anti-calreticulin antibodies. An excess amount of protein was loaded in the lanes labeled 2 to ensure detection of any NR3A or calreticulin at the cell surface. The subunit combinations used for transfection are indicated above each blot, and the positions of molecular size markers in kilodaltons are shown on the left. A representative experiment is shown; $n=3$. B, C, Surface localization of GFP-tagged NR3A. B, Left, Schematic drawing of expected transmembrane (TM) topology of NR3A-GFP is shown. Right, Protein immunoblots of HEK293T cells transfected with NR3A or NR3AGFP and probed with anti-NR3A antibody show an increase in NR3A molecular weight that corresponds to the molecular mass of GFP (27 kDa). No lower molecular weight bands were observed. $C$, Cells transfected with GFP-tagged NR3A alone or in combination with the other NMDA receptor subunits were immunostained in nonpermeabilizing (NP) conditions with anti-GFP antibody followed by a Texas Red-conjugated secondary antibody and imaged with filters for GFP and Texas Red. All four panels show raw superimposed confocal images combining NP anti-GFP antibody staining (red) and native GFP fluorescence from NR3A-GFP ( green). Yellow corresponds to the overlap of GFP immunostaining and GFP fluorescence and reflects NR3A-GFP expressed at the cell surface. Because the intensity of red immunostaining was brighter than was green GFP fluorescence, regions of overlapping can appear red-yellow. When expressed alone, NR3A-GFP exhibits a perinuclear and reticular fluorescence pattern, and no surface staining is observed. Cotransfection of NR1-1a/NR2A leads to the appearance of patches of fluorescence at the plasma membrane. Scale bar, $10 \mu \mathrm{m}$.

Grp78. Thus, NR3A is trapped in the biosynthetic pathway unless it is assembled with the NR1 subunit.

\section{NR1 colocalizes with the NR3 subunit at intracellular and plasma membrane sites}

Our experiments demonstrate that coexpression with NR1-1a reduces the ER retention and facilitates the surface expression of NR3A subunits. To determine whether NR3A-GFP colocalizes with NR1-1a at the plasma membrane, we double labeled surface receptors in nonpermeabilized cells using antibodies against the NR1 subunit and GFP (to intensify selectively the surface green fluorescence of NR3A-GFP). Figure $7 B$ shows overlap of NR1-1a and NR3A-GFP at the plasma membrane when they are coexpressed in HEK293T cells. Both subunits were colocalized in elongated plasma membrane patches, with only occasional clustering observed.

Extensive intracellular colocalization of NR1-1a and NR3AGFP was also observed in detergent permeabilized cells (Fig. 7A). Confocal analysis of the subcellular colocalization revealed that coexpression with NR1-1a alters the reticular pattern of NR3AGFP fluorescence (compare with Fig. 4C, top panels) and results in the appearance of intracellular receptor-rich domains, which displayed positive immunostaining for both subunits: small punctate clusters (mean diameter $=0.81 \pm 0.15 \mu \mathrm{m} ; n=17$ ) and irregular, plaque-like structures $(2.03 \pm 0.03 \mu \mathrm{m} ; n=31)$. The coincident patterns of intracellular and surface distribution of NR1-1a and NR3A-GFP, together with the changes in subcellular localization and surface expression of NR3A induced by coexpression of the NR1-1a subunit, indicate that NR3A subunits must coassemble with NR1 to allow the receptor complex to exit the ER and be inserted at the plasma membrane.

\section{DISCUSSION}

We have investigated the intracellular trafficking and surface expression of the NR3A NMDA receptor subunit in the presence and absence of NR1-1a and NR2A. We show that NR3Acontaining complexes are assembled in the ER before they can be 

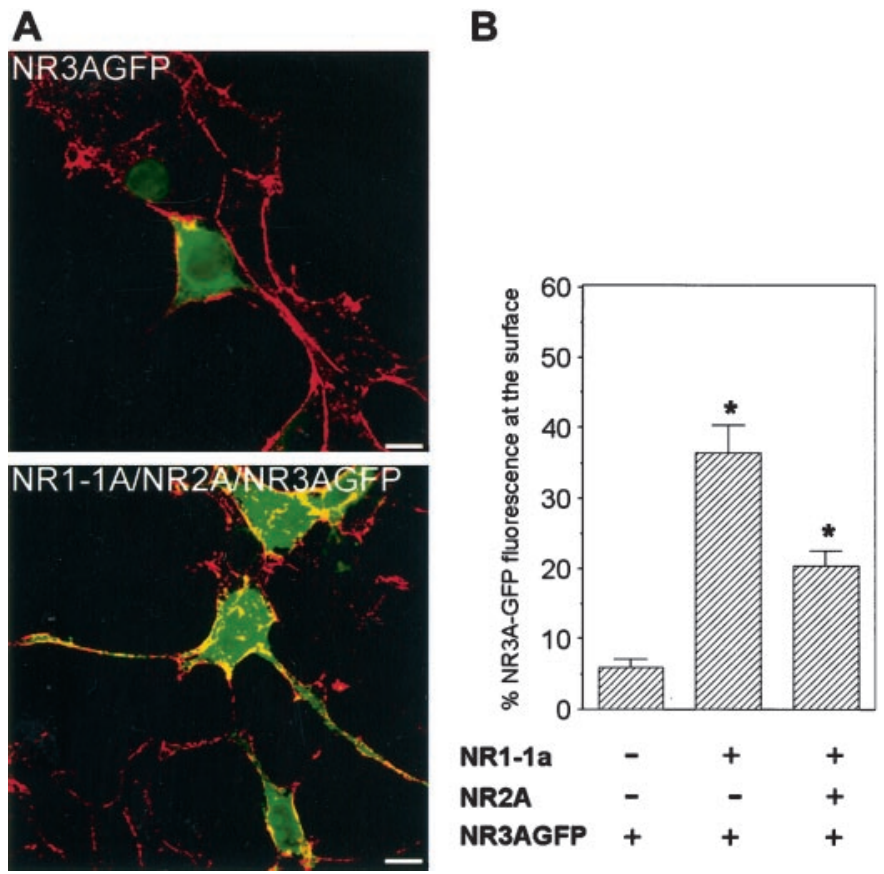

Figure 5. Measurement of the relative amount of NR3A-GFP at the surface in the presence of the NR1-1a subunit. Transfected HEK293T cells were incubated with tetramethylrhodamine-conjugated Concanavalin A (red fluorescence) to label the surface of the cell. A, NR3A-GFP does not colocalize with tetramethylrhodamine-conjugated Concanavalin A when expressed by itself, but significant overlap (yellow) is seen when NR3A-GFP is cotransfected with NR1-1a/NR2A. Superimposed images of GFP and rhodamine channels are shown. $B$, Measurement of relative cell surface expression of NR3A-GFP fluorescence in the presence or absence of the other NMDA receptor subunits is shown. Each vertical bar represents the mean of 35-39 cells from three independent experiments; ${ }^{*} p<0.001$ (vs NR3AGFP group), ANOVA followed by Student-Newman-Keuls multiple comparisons test. Scale bars, $10 \mu \mathrm{m}$.

transported to later stages of the biosynthetic pathway and inserted into the plasma membrane. Coexpression with NR1-1a but not NR2A subunits is necessary for the ER export and surface expression of NR3A-containing receptors. Although complexes containing only NR1-1a and NR3A can progress through the secretory pathway and are found at the plasma membrane, the presence of the NR2A subunit in the complex is required for receptor function.

\section{Functional properties of recombinant NMDA receptors containing the NR3A subunit}

NR3A coassembles with NR1-1a and NR2A NMDA receptor subunits to form an NMDA-activated channel. NMDA channels incorporating the NR3A subunit are inserted into the plasma membrane with the NR3A N-terminal GFP tag exposed at the extracellular surface, consistent with NR3A having the putative transmembrane topology of glutamate receptor subunits (Hollmann et al., 1994) and further supporting the idea that NR3A is an integral part of the functional receptor complex. In agreement with results from single-channel recordings in oocytes (Das et al., 1998), recombinant receptors containing NR3A can be distinguished from NR1-1a/NR2A heteromers because they display a reduced single-channel conductance, longer open times, and a lower relative $\mathrm{Ca}^{2+}$ permeability.
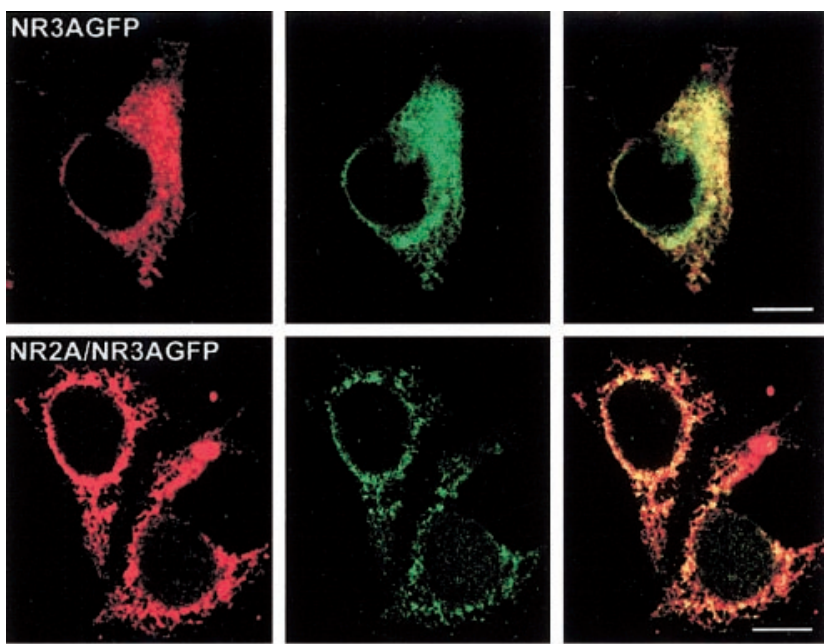

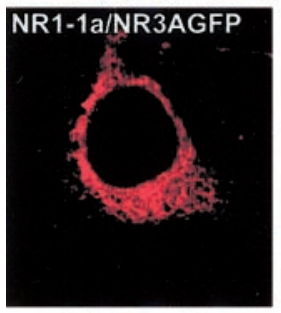

Calreticulin

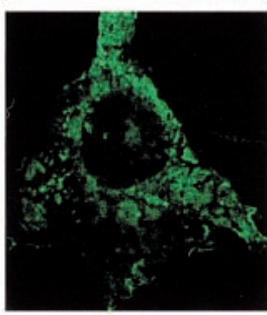

GFP-channel

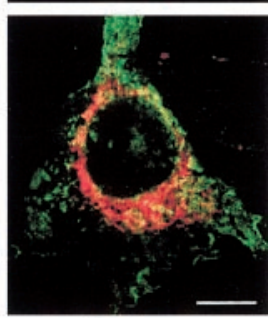

Merge
Figure 6. NR3A-GFP is retained in the ER in the absence of the NR1 subunit. Immunofluorescence with anti-calreticulin antibody (red; left column), NR3A-GFP fluorescence ( green; GFP-channel, middle column), and merged confocal fluorescence images (right column) indicate colocalization of NR3A-GFP with calreticulin (ER marker) in the absence of NR1-1a. Scale bars, $10 \mu \mathrm{m}$.

One feature that was thought to differentiate NMDA receptors from other members of the glutamate receptor family is their high relative $\mathrm{Ca}^{2+}$ permeability (Monyer et al., 1992). Our results show that NMDA receptor channels including the NR3A subunit have a low permeability to $\mathrm{Ca}^{2+}$ ions, as suggested previously (Das et al., 1998). Incorporation of NR3A reduces the relative $\mathrm{Ca}^{2+}$ permeability of the channel by more than fivefold when compared with cells expressing only NR1-1a and NR2A. Since our single-channel studies show that NR1-1a, NR2A, and NR3A assemble to form a mixed population of receptors in HEK293 cells, the $\mathrm{Ca}^{2+}$ permeability of NR3A-containing receptors that we calculated from reversal potential shifts is probably an overestimate, because of the contribution to the whole-cell response of receptors composed of only the NR1-1a and NR2A subunits. NMDA receptors containing the NR3A subunit are thus no more permeable to $\mathrm{Ca}^{2+}$ than are other non-NMDA glutamate receptors (Dingledine et al., 1999).

$\mathrm{Ca}^{2+}$ flux through NMDA receptors is thought to initiate intracellular signaling events that trigger certain forms of synaptic plasticity, such as long-term potentiation and depression (Malenka and Nicoll, 1999), and may underlie the role that NMDA receptors play in the induction of cell death (Sattler et al., 1999). Regulation of the expression of the NR3A subunit might thus constitute a mechanism for modulating the potential for synaptic plasticity or may serve a neuroprotective function under conditions that induce $\mathrm{Ca}^{2+}$ accumulation in neurons. 
A

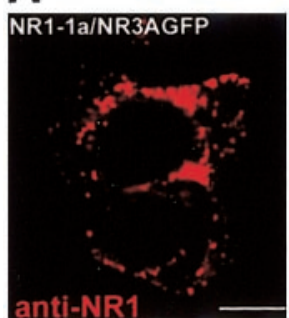

B
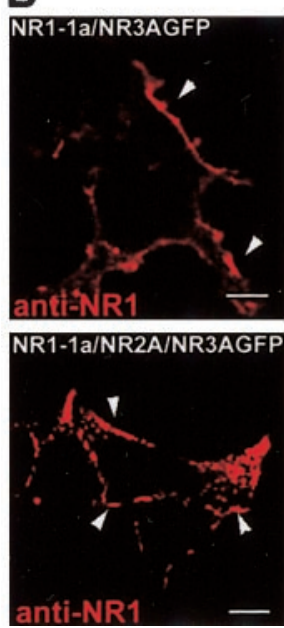

Permeabilized

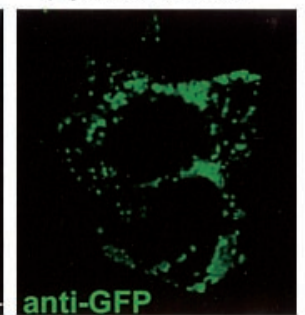

Non-permeabilized
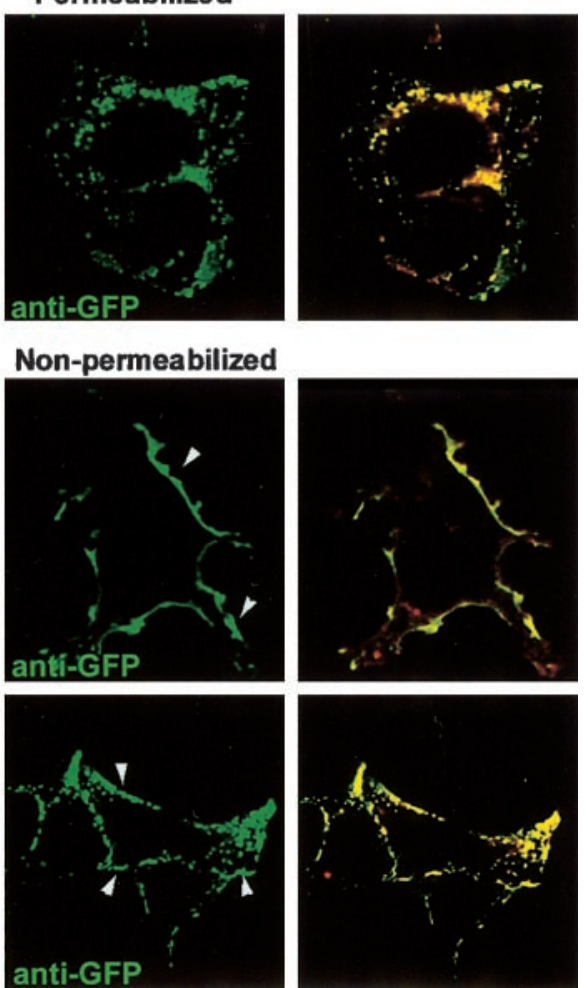
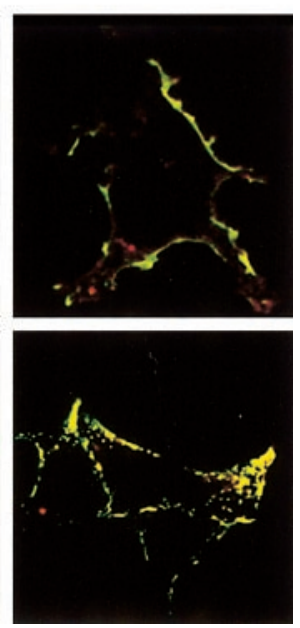

Figure 7. NR3A-GFP colocalizes with the NR1-1a subunit at intracellular and plasma membrane sites. HEK293T cells were transfected with the indicated combinations of NMDA receptor subunits. Immunofluorescence to NR1 (left column) and GFP (middle column) was performed in permeabilized $(A)$ and nonpermeabilized $(B)$ cells to analyze patterns of NR1-1a/NR3A-GFP colocalization. Confocal microscopy sections are shown. Areas of overlapping appear yellow (right column). Arrowheads point to membrane patches where both subunits are found. Scale bars, $10 \mu \mathrm{m}$.

\section{Role of the NR1 subunit in the cell surface targeting of NMDA receptors}

The cellular mechanisms that control the functional expression of low $\mathrm{Ca}^{2+}$-permeable, NR3A-containing receptors have not been studied. Our results reveal that the trafficking of NMDA receptors containing NR3A to the cell surface depends on their subunit composition, specifically on the presence of the NR1 subunit in the receptor complex. NR3A can associate independently with both NR1-1a and NR2A, which provides a biochemical substrate for multiple subunit combinations. However, NR2A/NR3A heteromers were not detected at the cell surface and were retained in the ER. In contrast, formation of NR1-1a/NR2A/NR3A complexes did result in functional NR3A-containing receptors at the cell surface. This may occur because of some defect in the folding or assembly of the receptor complex in the absence of the NR1 subunit, causing the receptor to be subject to quality control in the ER and preventing its transport to the plasma membrane (Ellgaard et al., 1999). In support of this hypothesis, we found that coexpression of NR1-1a and NR3A resulted in the appearance of intracellular vesicle-like structures that contain both subunits and are able to exit the ER.

Previous studies had suggested that NR1 requires the coexpression of NR2 subunits to be targeted to the cell surface (McIlhinney et al., 1996). In cultured hippocampal neurons, $\sim 90 \%$ of NR2 subunits are expressed in the plasma membrane, whereas there is a much larger amount of intracellular NR1 subunits (Hall and Soderling, 1997). It was therefore proposed that cell surface expression of NMDA receptors could be regulated by the synthesis of the NR2 subunit, which would coassemble with the intracellular pool of NR1. Our data extend this interpretation to suggest that only properly folded and assembled NMDA receptor complexes are targeted to the cell surface. These complexes must include at least one NR1 subunit and either an NR3A or an NR2 subunit. In this case, the least abundant subunit might become the limiting factor. In fact, we note that coexpression of NR1-1a, NR2A, and NR3A, which results in the appearance of a mixed population of functional NMDA receptor channels (NR1-1a/NR2A and NR1-1a/NR2A/ NR3A), produced increased ER accumulation of NR3A and resulted in lower expression of NR3A at the cell surface. This supports the idea that limiting amounts of NR1 subunits are available for assembly with NR3A in the presence of NR2 under these conditions.

The signaling machinery that regulates the progression of membrane proteins through the biosynthetic pathway is largely unknown. Subunit hetero-oligomerization has been shown to be required for surface expression of a growing list of ion channels, including $\mathrm{GABA}_{\mathrm{A}}$ receptors, acetylcholine receptors, voltagegated potassium channels, and ATP-sensitive potassium channels $\left(\mathrm{K}_{\mathrm{ATP}}\right)$ (Paulson et al., 1991; Gorrie et al., 1997; Zerangue et al., 1999; Manganas and Trimmer, 2000), and it is emerging as a common mechanism to restrict functional expression to only certain subunit combinations. A recent study has shed light on one of the mechanisms linking subunit assembly to intracellular trafficking via the identification of a new ER retention signal (Zerangue et al., 1999). The presence of this ER retention motif (RXR) prevents the exit from the ER of partially or incorrectly folded $\mathrm{K}_{\mathrm{ATP}}$ channels. Assembly of $\mathrm{K}_{\mathrm{ATP}}$ channels of defined stoichiometry masks this signal and allows insertion of the complex at the plasma membrane. The RXR motif is present in the $\mathrm{C}$ terminus of the NR1-1a, NR3A, and the NR2B NMDA receptor subunits. The $\mathrm{C}$-terminal domain of other NR2 subunits contains a previously characterized (KKXX) ER retention signal. Thus, the presence of the NR1 subunit might be required for the assembly of properly folded NMDA receptors, by masking ER retention signals and allowing efficient membrane insertion. We cannot, however, exclude the possibility that the NR1 subunit contains forward trafficking signals that are required for the surface expression of NMDA receptor complexes. Interestingly, receptor complexes formed by NR1-1a/NR3A do appear to fold and assemble sufficiently to pass through the ER quality control mechanism, because they are expressed on the cell surface. The fact that these receptors fail to function may be explained by the fact that neither NR1-1a nor NR3A has been shown to have a glutamate binding site.

Additional mechanisms not operating in HEK293T cells may be involved in the localization of the receptor in neurons. The NR3A subunit is enriched in brain postsynaptic densities, but the mechanisms that mediate its localization to postsynaptic sites have not been investigated (Das et al., 1998). In our heterologous expression system, we did not detect significant surface clustering of NR3A-containing receptors. This is consistent with the idea that clustering and stabilization of NMDA receptors at specific sites at the plasma membrane are mediated by interactions of proteins of the PSD-95 family (PSD-93/chapsyn110, PSD-95/ SAP90), which are absent in HEK293T cells, with a short peptide motif at the $\mathrm{C}$ terminus of NR2 subunits $[\mathrm{E}(\mathrm{T} / \mathrm{S}) \mathrm{XV}]$ (Kornau et 
al., 1995; Kim et al., 1996). Thus, although the NR1-1a subunit is sufficient for the trafficking and plasma membrane expression of NR3A-containing receptors, the presence of NR2 subunits could regulate the targeting, anchoring, and stabilization of functional NR3A complexes at specific synaptic sites.

\section{REFERENCES}

Bliss TV, Collingridge GL (1993) A synaptic model of memory: longterm potentiation in the hippocampus. Nature 361:31-39.

Burnashev N, Zhou Z, Neher E, Sakmann B (1995) Fractional calcium currents through recombinant GluR channels of the NMDA, AMPA and kainate receptor subtypes. J Physiol (Lond) 485:403-418.

Choi DW (1988) Glutamate neurotoxicity and diseases of the nervous system. Neuron 1:623-634.

Ciabarra AM, Sullivan JM, Gahn LG, Pecht G, Heinemann S, Sevarino KA (1995) Cloning and characterization of $\chi-1$ : a developmentally regulated member of a novel class of ionotropic glutamate receptor family. J Neurosci 15:6498-6508.

Colquhoun D, Sigworth FJ (1995) Fitting and statistical analysis of single channels. In: Single channel recording, 2nd Edition (Sakmann B, Neher E, eds), pp 483-588. New York: Plenum.

Constantine-Paton M, Cline HT, Debski E (1990) Patterned activity, synaptic convergence, and the NMDA receptor in developing visual pathways. Annu Rev Neurosci 13:129-154

Das S, Sasaki YF, Rothe T, Premkumar LS, Takasu M, Crandall E, Dikkes P, Conner DA, Rayudu PV, Cheung W, Chen HSV, Sucher NJ, Lipton SA, Nakanishi N (1998) Increased NMDA current and spine density in mice lacking the NMDA receptor subunit NR3A. Nature 393:377-381.

Dingledine R, Borges K, Bowie D, Traynelis SF (1999) The glutamate receptor ion channels. Pharmacol Rev 51:7-61.

Dubridge RB, Tang P, Hsia HC, Leong P-M, Miller JH, Calos MP (1987) Analysis of mutation in human cells by using an Epstein-Barr viral shuttle system. Mol Cell Biol 7:379-387.

Durand GM, Bennett MV, Zukin RS (1993) Splice variants of the $\mathrm{N}$-methyl-D-aspartate receptor NR1 identify domains involved in regulation by polyamines and protein kinase C. Proc Natl Acad Sci USA [Erratum (1993) 90:9739] 90:6731-6735.

Ehlers MD, Zhang S, Bernhardt JP, Huganir RL (1996) Inactivation of NMDA receptors by direct interaction of calmodulin with NR1 subunit. Cell 84:745-755.

Ellgaard L, Molinari M, Helenius A (1999) Setting the standards: quality control in the secretory pathway. Science 286:1882-1888.

Gorrie GH, Vallis Y, Stephenson A, Whitfield J, Browning B, Smart TG, Moss SJ (1997) Assembly of GABAA receptors composed of alpha1 and beta2 subunits in both cultured neurons and fibroblasts. J Neurosci 17:6587-6596.

Green WN, Millar NS (1995) Ion-channel assembly. Trends Neurosci 18:280-287.

Hall RA, Soderling TR (1997) Differential surface expression and phosphorylation of the $N$-methyl-D-aspartate receptor subunits NR1 and NR2 in cultured hippocampal neurons. J Biol Chem 272:4135-4140.

Hollmann M, Boulter J, Maron C, Beasley L, Sullivan J, Pecht G, Heinemann S (1993) Zinc potentiates agonist-induced currents at certain splice variants of the NMDA receptor. Neuron 10:943-954

Hollmann M, Maron C, Heinemann S (1994) N-glycosylation site tagging suggests a three transmembrane domain topology for the glutamate receptor GluR1. Neuron 13:1331-1343.

Kim E, Cho KO, Rothschild A, Sheng M (1996) Heteromultimerization and NMDA receptor-clustering activity of Chapsyn-110, a member of the PSD-95 family of proteins. Neuron 17:103-113.

Klausner RD, Donaldson JG, Lippincott-Schwartz J (1992) Brefeldin A: insights into the control of membrane traffic and organelle structure. J Cell Biol 116:1071-1080.

Kornau HC, Schenker LT, Kennedy MB, Seeburg PH (1995) Domain interaction between NMDA receptor subunits and the postsynaptic density protein PSD-95. Science 269:1737-1740.

Lin JW, Wyszynski M, Madhavan R, Sealock R, Kim JU, Sheng M (1998) Yotiao, a novel protein of neuromuscular junction and brain that interacts with specific splice variants of NMDA receptor subunit NR1. J Neurosci 18:2017-2027.

Lippincott-Schwartz J, Donaldson JG, Schweizer A, Berger EG, Hauri HP, Yuan LC, Klausner RD (1990) Microtubule-dependent retrograde transport of proteins into the ER in the presence of brefeldin A suggests an ER recycling pathway. Cell 60:821-836.

Luo J, Wang Y, Yasuda RP, Dunah AW, Wolfe BB (1997) The majority of $N$-methyl-D-aspartate receptor complexes in adult rat cerebral cortex contain at least three different subunits (NR1/NR2A/NR2B). Mol Pharmacol 51:79-86.

Malenka RC, Nicoll RA (1999) Long-term potentiation-a decade of progress? Science 285:1870-1874.

Manganas LN, Trimmer JS (2000) Subunit composition determines Kv1 potassium channel surface expression. J Biol Chem 275:29685-29693.

Mayer ML, Westbrook GL (1987) Permeation and block of $N$-methyl-Daspartic acid receptor channels by divalent cations in mouse cultured central neurones. J Physiol (Lond) 394:501-527.

McIlhinney RA, Molnar E, Atack JR, Whiting PJ (1996) Cell surface expression of the human $N$-methyl-D-aspartate receptor subunit 1a requires the co-expression of the NR2A subunit in transfected cells. Neuroscience 70:989-997.

McIlhinney RA, Le Bourdelles B, Molnar E, Tricaud N, Streit P, Whiting PJ (1998) Assembly intracellular targeting and cell surface expression of the human $N$-methyl-D-aspartate receptor subunits NR1a and NR2A in transfected cells. Neuropharmacology 37:1355-1367.

Monyer H, Sprengel R, Schoepfer R, Herb A, Higuchi M, Lomeli H, Burnashev N, Sakmann B, Seeburg PH (1992) Heteromeric NMDA receptors: molecular and functional distinction of subtypes. Science 256:1217-1221.

Monyer H, Burnashev N, Laurie DJ, Sakmann B, Seeburg PH (1994) Developmental and regional expression in the rat brain and functional properties of four NMDA receptors. Neuron 12:529-540.

Nagaya N, Papazian DM (1997) Potassium channel alpha and beta subunits assemble in the endoplasmic reticulum. J Biol Chem 272:3022-3027.

Neher E (1992) Correction for liquid junction potentials in patch clamp experiments. Methods Enzymol 207:123-131.

Niethammer M, Kim E, Sheng M (1996) Interaction between the C terminus of NMDA receptor subunits and multiple members of the PSD-95 family of membrane-associated guanylate kinases. J Neurosci $16: 2157-2163$.

Paulson HL, Ross AF, Green WN, Claudio T (1991) Analysis of early events in acetylcholine receptor assembly. J Cell Biol 113:1371-1384.

Sattler R, Xiong Z, Lu WY, Hafner M, MacDonald JF, Tymianski M (1999) Specific coupling of NMDA receptor activation to nitric oxide neurotoxicity by PSD-95 protein. Science 284:1845-1848.

Schneggenburger R (1996) Simultaneous measurement of $\mathrm{Ca}^{2+}$ influx and reversal potentials in recombinant $N$-methyl-D-aspartate receptor channels. Biophys J 70:2165-2174.

Stern P, Behe P, Schoepfer R, Colquhoun D (1992) Single channel conductances of NMDA receptors expressed from cloned cDNAs: comparison with native receptors. Proc R Soc Lond [Biol] 250:271-277.

Stern-Bach Y, Bettler B, Hartley M, Sheppard PO, O'Hara PJ, Heinemann SF (1994) Agonist selectivity of glutamate receptors is specified by two domains structurally related to bacterial amino acid-binding proteins. Neuron 13:1345-1357.

Sucher NJ, Akbarian S, Chi CL, Leclerc CL, Awobuluyi M, Deitcher DL, Wu MK, Yuan JP, Jones EG, Lipton SA (1995) Developmental and regional expression pattern of a novel NMDA receptor-like subunit (NMDAR-L) in the rodent brain. J Neurosci 15:6509-6520.

Tsien JZ, Huerta PT, Tonegawa S (1996) The essential role of hippocampal CA1 NMDA receptor-dependent synaptic plasticity in spatial memory. Cell 87:1327-1338.

Wo ZG, Oswald RE (1994) Transmembrane topology of two kainate receptor subunits revealed by N-glycosylation. Proc Natl Acad Sci USA 91:7154-7158

Wyszynski M, Lin J, Rao A, Nigh E, Beggs AH, Craig AM, Sheng M (1997) Competitive binding of alpha-actinin and calmodulin to the NMDA receptor. Nature 385:439-442.

Zerangue N, Schwappach B, Jan YN, Jan LY (1999) A new ER trafficking signal regulates the subunit stoichiometry of plasma membrane K(ATP) channels. Neuron 22:537-548. 